\title{
Hairy Cell Leukemia: the good news of a bad disease
}

\author{
Mónica Seidi, Guadalupe Benites, Almerindo Rego \\ Hospital de Santo Espírito da Ilha Terceira
}

\begin{abstract}
Hairy Cell Leukemia $(\mathrm{HCL})$ is an uncommon chronic B cell Lymphoproliferative disorder characterized by the accumulation of a small mature B cell lymphoid cells with abundant cytoplasm and "hairy" projections within the peripheral blood smear, bone marrow and splenic red pulp. Most patients with $\mathrm{HCL}$ present with symptons related to splenomegaly or cytopenias, including some constitucional symptons, however one quarter of them is asymptomatic and is referred due to incidental findings.

The authors decided to report a clinical case of hairy cells leukemia in an asymptomatic patient due to the rarity of this neoplasia (2\% of all leukemias and less than $1 \%$ of limphoids neoplasms) and because it corresponds to the most successfully treatable leukemia.

Palabras clave: Citopenias. Esplenomegalia. Enfermedad linfoproliferativa. Leucemia de células peludas.

Keywords: Cytopenias. Splenomegaly. Lymphoproliferative disease. Hairy cells leukemia
\end{abstract}

\section{Introduction}

Hairy cell leukemia $(\mathrm{HCL})$ is an uncommon B-cell lymphoproliferative disorder that affects adults, and was first reported as a distinct disease in 1958 (Bouroncle et al, 1958). ${ }^{1}$

The prevalence has been estimated at $2 \%$ of all forms of leukaemia and, of patients affected by lymphoproliferative diseases that comprise mature B or T cells, HCL accounts for $8 \%$ of cases and is $6-10$ times more rare than chronic lymphocytic leukemia (CLL). ${ }^{1,2}$

The disease presents in middle aged men, with a striking $5: 1$ male predominance. The median age at presentation is 50 years old. ${ }^{1,3}$

Most patients present with gradual onset of fatigue, others complain of symptons related to markedly enlarge spleen, and some come to attention because on infection, however in most cases, $\mathrm{HCL}$ is an indolent disorder whose course is dominated by pancytopenia. ${ }^{3}$

The purpose of this report was to create awareness of this uncommon presentation in an patient with no clinical symptons, but with bicytopenia.

\section{Case Report}

A 48-year-old man with history of obesity, dyslipidemia and renal lithiasis was refered to internal medicine clinicals with persistent asymptomatic bicytopenia since 2015. There were no other symptoms present and the physical examination was normal, including no peripheral lymphadenopathy, however by abdominal palpation was difficulted to detected splenomegaly due to his obesity.

Laboratory tests were repetead in the same day and revealed Haemoglobin concentration of $12.4 \mathrm{~g} / \mathrm{dl}$, red blood cell $(\mathrm{RBC})$ count $3.80 \times 10^{6} / \mathrm{L}$ total leukocyte count (TLC) of $3.96 \times 10^{3} / \mathrm{L}$, neutrophils count $3.15 \times 10^{3} / \mathrm{L}$ and platelets $56 \times 10^{9} / \mathrm{L}$, Sedimentation rate $54 \mathrm{~mm}$; Viral serologies for HIV, hepatitis, CMV and EBV were negative. The peripheral blood smear demonstrated moderated neutropenia and lymphocytosis. Electrophoresis showed a mono- clonal gamma peak. The CT abdominal scan revealed homogenea splenomegaly with no limphadenopathy present.

We decided to admit the patient in the ward to perform invasive exams such as a bone marrow aspiration which showed $66 \%$ of lymphoid cells with abundant cytoplasm and extensions suggesting the presence of hairy cells. The biopsy was inconclusive and the immunophenotyping of peripheral blood was done and revealed positivity for the immunophenotypic markers CD 19 (strong), CD20 (strong), CD 11c (strong), CD 103 (hairy cell marker) (strong), CD 5 and CD38 were negative. Tartrate resistant Acid phosphatase antibody was reactive.

The diagnosis of Hairy Cells Leukemia was done and the patient was refered to Hemato-Oncology department to initiate chemotherapy.

\section{Discussion}

$\mathrm{HCL}$ is a relatively rare form of leukemia characterized by an insidious onset, splenomegaly without lymphadenopathy, pancytopenia, dry bone marrow aspirates and the presence of abnormal mononuclear cells with hairy cytoplasmic projections in the peripheral blood, bone marrow and splenic red pulp. ${ }^{4,5}$ Only $10 \%$ of the patients have a sucessuful bone marrow aspiration due to $\mathrm{HCL}$ induced marrow fibrosis. ${ }^{1}$

Patients may be asymptomatic and the disease is identified because a full blood count is taken for an unrelated reason. Other patients present with symptons of cytopenia, particularly infections. Anemia is nearly universal and $75 \%$ of the case have thrombocytopenia and neutropenia, $20 \%$ with hypergammaglobulinemia.,

The basic mechanisms involved in the pathogenesis of $\mathrm{HCL}$ are poorly understood. Recent studies have demonstrated that the hairy cells are mature B cells. They have mutated IgH genes, suggesting postgerminal center, antigen-acquainted memory cells. They have low mitotic cycling rates and thus a protracted clinical course, but a highly activated cytokine 
transcription apparatus including a cytokine storm, which is responsible for diverse clinical and morphological features. ${ }^{5}$ Some studies indicate that virtually all cases are associated with V600E activating mutation in the serine/threonine kinase BRAF, which can be seen as a new diagnostic tool and a potential treatment target. Exposures to ionizing radiation, EBV, organic chemicals, woodworking and farming have been mentioned as possible causes. ${ }^{3,4}$

The hairy cells have a characteristic histochemical staining pattern with tartrate-resistant acidphosphatse (TRAP). On immunophenotyping the cells coexpress the antigens CD11C, CD 20, CD 22, CD25, CD 103,CD 123.

The differential diagnosis of HCL includes other small B cell lymphoproliferative disorders associated with splenomegaly, such as chronic lymphocytic leukemia, prolymphocytic leukemia, splenic marginal zone lymphoma, the variant form of HCL, and the mantle cell lymphoma. These entities can usually be excluded based on morphologic and immunophenotypic features. It is important to diagnose these entities accurately as they have different clinical and biological features, particularly regarding the response to -interferon. ${ }^{3,4,5}$ Many patients with HCL can be observed for months or years after the diagnosis is established before requiring treatment. There is no clear advantage to early treatment; therapy is indicated only when the patient develops one or more symptons: significant cytopenias (absolute neutrophil count < $1000 /$ microL with repetead infections, hemoglobin $<11.0$ $\mathrm{g} / \mathrm{dl}$ or bleeding due to platelet count $<100,000 /$ microL), symptomatic splenomegaly or adenopathy or constitutional symptons. ${ }^{6,7,8}$

Regarding treatment options, it has been revolutionized with the advent of interferon (IFN)-alpha and purine analogues (PA), specifically pentostatin or cladribina for a single course which provide an overall response rate of $75-100 \%$. Rituximab has also been used to treat relapsed/refractory HCL with an overall response of $80 \% .^{5}$

We have reported this case of HCL which was suspected on morphology, and diagnosis was confirmed by immunohistochemistry. Recognising the features of this leukaemia and considering it in the differential diagnosis in the right clinical setting is crucial to avoid a misdiagnosis of this most successfully treatable leukaemia.

\section{References}

1. Jones G, Parry-Jones N, Wilkins B, Else M, Catovsky D.Revised guidelines for the diagnosis and management of hairy cell leukaemia and hairy cell leukaemia variant. www.bschguidelines.com. Acessed in May 2016

2. Junior A, Bueno A, Paula E, Clarindo M, Gerhardt J. Hairy Cell Leukemia: therapeutic options, emphasis on ambulatorial regimen; Rev Bras. Oncologia Clinica 2005. Vol 2 No6 (Set/Dez 29-30)

3. Damon L, Andeadis C. Hairy Cells Leukemia. Current Medical Diagnosis \&Treatment 2016 chapter 13; 527-528

4. Tallman M; Aster Jon. Clinical features and diagnosis of hairy cell leukemia. www. uptodate.com. Acessed in May 2016

5. Kataria S, Sanjay K, Rajeev S, Gajender S, Uma S, Raghuveer I Hairy Cell Leukemia: A Diagnostic Dilemma. Biomedicine International (2011) 2: 36-38

6. Tallman Martin. Treatment of Hairy Cell Leukemia. www.uptodate.com Acessed in May 2016

7. Krau E. Infectious complications in hairy cell Leukemia. Leuk Lymphoma 2011; 52 Suppl 2:50

8. Teodorescu M, Engeberg MC, Johansen $P$ et al. Risk factors for severe infection in patients with hairy cell leukemia in Denmark. Dan Med Bull 2010; 57: A4216. 